\title{
Learning from Feedback on Work-Related Learning: Skills Acquisition and Reality Check
}

\author{
D Palmer-Brown*, FF Cai* ${ }^{* *}$ P Patel ${ }^{* * *}$ \\ ${ }^{*}$ London Metropolitan University, ${ }^{* *}$ Anglia Ruskin University, ${ }^{* * *}$ London Metropolitan University
}

\begin{abstract}
An increasingly strong focus of higher education is now placed on the acquisition of skills that will strengthen the employability prospects of learners. This has led to, among other provisions, the embedding of work-related, workbased and project-based components into the academic curriculum for which newer forms of assessment and assessment feedback are necessary.

This paper reports on a pilot study which aims to understand the relationship between learning development in the last stages of an undergraduate's journey and their first experiences of employment. The study was conducted with a small cohort of computing graduates whose degree includes an embedded final year work-related learning module. The outcome of this study shows that whilst employability skills were reported to have indeed improved through this module, the graduates felt ill-prepared for the productivity demands of the workplace. There was also a strong reflection among them now in employment that an additional exposure, as part of the module, to formal appraisal techniques and competency terminology utilised throughout industry sectors would have had an added benefit.
\end{abstract}

Keywords: feedback, work-related learning, employability, graduate skills, learning agreements

\section{Introduction}

The past decade has seen the fortifying of employability skills acquisition into Higher Education (HE) programmes in all subject disciplines. On the one hand, the priority placed by students on developing generic, transferable and work-related skills as an integral part of their academic study in order to enhance their employment prospects has never been higher. On the other hand, employers continue voicing their strong concerns over graduates who are lacking necessary problem-solving, business communication and team-working skills required in the workplace. These dual demands have been responded to by the HE sector with the introduction and embedding of several work-related learning initiatives into the academic curriculum.

Venables \& Tan (2009) describe work-related learning as a form of experiential learning where students learn through their experiences rather than from direct transmission of material. The term work-related learning is sometimes used to mean that learning which is developed and experienced in the workplace, Simons \& Ruijters (2008); possibly outside an academic programme. This is seen to be a form of training and is perhaps better termed work-based learning, where the learning experiences arise directly from the work tasks to hand.

Work-related learning initiatives are particularly predominant in the computing, science and business disciplines where most take the form of a module with a work placement opportunity and a series of assessments, for example Clements \& Cord (2013). Many programmes include such a module in the final year of study, whereas McKinnon \& McCrae (2012) believe that work-related activities should be embedded into the first year curriculum in order to allow for early exposure to the benefits of enhancing employment skills. The work of Jollands et al. (2012) on project-based learning for engineers gives an insight into how 'aspects of undergraduate experiences assisted with their transition into the workplace'. Graduates (and their managers) were interviewed to ascertain their work-readiness in a number of skills including project management, problem solving and communication. The study explores the degree of work-readiness 
but does not examine the use of assessment feedback and how that was understood and deciphered by the recipient and which elements have direct applicability and effectiveness to workplace tasks. Hopkins (2008) places emphasis on engaging with college leavers in order to learn how they experience the benefits of work-related learning.

Learning has many facets: theory, experience, reflection, practice and social interaction. Lappia (2011) acknowledges that all these elements should ideally come into play during a work-related learning arrangement. Additionally, learners also learn effectively by the type of feedback they receive, including explicit improvement indicators. Although Clements \& Cord (2013) highlight the importance of choosing assessment methods with care, there is little evidence as to the type of feedback, and the effectiveness of it in the preparation of new graduates, which has been provided on their 'experiential learning programme'. Initiatives such as CDIO (Conceive-DesignImplement-Operate) for engineers and PBL (Problem-Based Learning) for medical scientists have forged the path to actively instilling experiences of workplace requirements into the academic syllabus.

Given that there is currently a profusion of research activity and ever-increasing output of publications describing and evaluating assessment feedback types, a recent substantial work from Evans (2013) represents a monumental attempt at a systematic review of the literature where initial searches found 1,131 possible articles. Rowe \& Wood (2008) conclude that assessment feedback as a motivator is particularly well received by students. Jessop et al. (2013) report that students on a programme with a work placement receive significantly more oral feedback. One useful method of feedback provision involves self-assessment and reflection, but Jackson (2014) finds that when it comes to undergraduates assessing their own capability of employment skills there can be varying degrees of over and under rating.

Given the prominent emphasis on work-related learning within the HE curriculum, there appears to be insufficient coverage of feedback mechanisms which are directly relevant to assessment and practice in the work-related learning context. The exploratory hypothesis is that current feedback practices in this area lack rigour and precision and should ideally reflect those used in mainstream commercial and public industry sectors.

\section{Methodology}

In this pilot study an online survey questionnaire and qualitative interview methodology have been employed to elicit opinion and commentary on the extent to which assessment criteria and the feedback received map onto the participant's ability to perform work tasks. The online survey is designed to re-engage the new graduates and remind them of their experiences on completing assessment on a work-related learning module. A follow-up interview was based on a semi-structured question framework with opportunity for open-ended discussion. Interview participants were encouraged to describe workplace practices with examples where possible and also to make comparisons between their work-related learning experiences and their current work experiences.

Graduates from the 2014 cohort of three computing degree programmes who had completed a work-related learning module were included for participation. The online 
survey was kept brief (10 questions) to generate as much interest as possible, and 41 leavers out of 84 actually took the survey.

\section{The work-related learning module}

Students on a Computing related set of undergraduate programmes undertake a 6 month work-related learning module whose main aim is to enhance and extend their learning experience by applying academic skills to tackling real life problems in the workplace. At the start of the module, all students develop a learning agreement in conjunction with stakeholders. The learning agreement specifies the way in which learning outcomes will be developed and how they will be evidenced. The assessment tool is a learning portfolio which comprises of a weekly learning log, employer evaluation, a business report with supporting evidence/artefacts and a final presentation/demonstration. Feedback mechanisms used include criteria-based written comments from the employer and also annotations on the portfolio report by the tutor. Verbal feedback is given during the final presentation, which also includes an element of peer feedback.

\section{Results and Discussion}

The responses to the online survey and subsequent interviews give an indication of the benefits and the potential gaps in the work-related learning experience. Survey questions based on the improvement of skills as a direct result of the work-related learning module were posed. The results give some insight into the perception of graduates at that important transitional period of leaving the university educational environment and spending 6+ months in the workplace. However it is the individual interviews that have shed more light on other aspects of the perceptions of graduates in the workplace.

The results of responses to questions are discussed below which asked participants to rate their effectiveness at six core skills: before taking the work-related module, after taking it and at their current workplace. In general there is a marked improvement in skills acquisition and enhancement during the work-related learning module, with the most significant improvement being in teamwork skills. This is reassuring as that is one of the main learning outcomes of the module. More interestingly though is the perceived improvement of several other skills at the workplace, in particular organisation and time management. Professional conduct appears to be an area needing more focus within the module, as it is only in the workplace that respondents relate an improvement in this aspect.

\section{Communication and Interpersonal skills}

These skills would have been practiced repeatedly during the module, with verbal and written communications with clients, employers, tutors and peers; and culminating in a formal presentation.

Therefore an improvement during the module is to be expected, but in this case there is a further and extremely significant improvement beyond the module $-73 \%$ responded in the 'good' and 'very good' categories after the module, which rose to $93 \%$ in the workplace. Graduates relate that the positive feedback they received during the module resulted in them becoming more confident and competent in this skill in the workplace. 


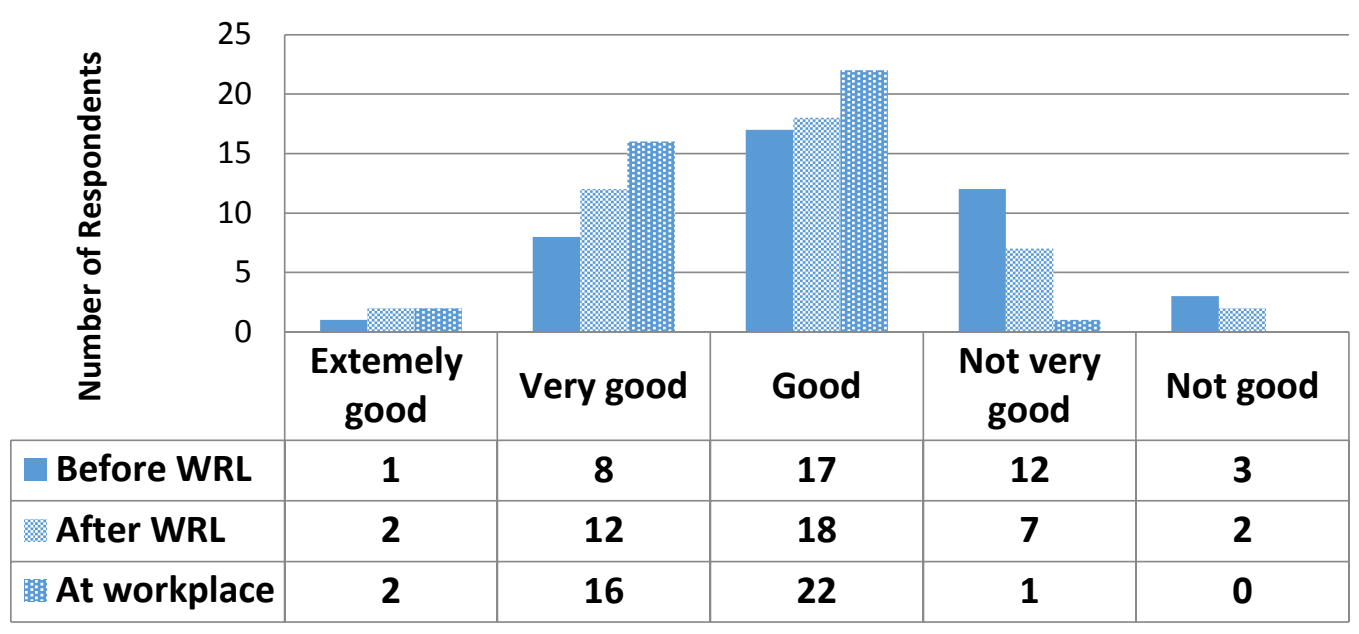

Figure 1. Effectiveness at Communication and Interpersonal skills

\section{Teamwork skills}

These skills appear to have improved dramatically during the module but showed barely any change thereafter. Many participants comment that although they are part of a team (varying from 2-8) in the workplace they have not yet had an opportunity to contribute fully and have instead being allocated manageable tasks to be completed under supervision. This suggests an underdeveloped knowledge and experience of what it means to be a member of a team, making a contribution to its overall achievement by completing designated tasks to a high standard and in a timely manner.

\section{Initiative and Problem-solving skills}

These skills showed the most movement in ratings with half of all respondents moving from the 'not very good' category at the end of the module to the 'good' category at the workplace. This result may be attributed to the prominence given during the undergraduate programme to mastery of these skills as being extremely desirable to potential employers. Some participants comment that they were formally tested on these skills during the job selection process; others relate their experiences of having to answer questions in this area during a job interview. These skills have a heightened interest for computing graduates as their perception is that is what employers are particularly interested in.

\section{Organisation and Time Management skills}

These skills have the most significant movement in terms of respondents' perception of how effective they have become at them in the workplace. In part this may be explained by the fact that several graduates were either on temporary contracts or paid hourly which may have enabled them to structure their time more effectively in order to meet deadlines. During the interviewing several participants related that they surprised themselves at how they had made these skills a priority when commencing employment, whereas they had given them very little thought during University life.

\section{Professional Conduct skills}

During the module, respondents were not very good (80\%) at these skills and there was very little improvement during the module. However, in the workplace that belief had been minimised to just $17 \%$. Workplace induction and initial training may have 
attributed to this improvement. During the module skills in this area related to student awareness of codes of dress, behaviour expectations, confidentiality and diversity.

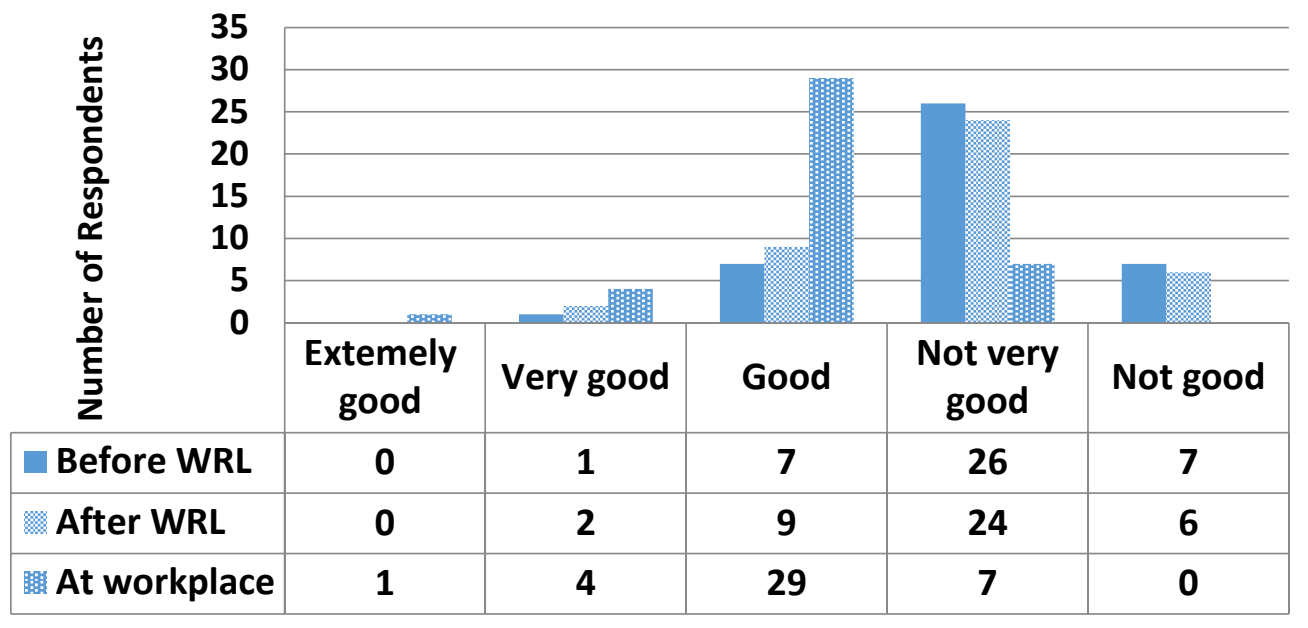

Figure 2. Effectiveness at Professional Conduct skills

Jollands et al. (2012) pinpoint a work-readiness skill termed ethical considerations which in their study was found to be sometimes misunderstood by both graduates and their managers. Understanding professional and ethical implications and how to apply them appears to be an area that requires more attention - something which professional bodies can help with. Trustworthiness is not only difficult to measure but is also challenging to teach, learn and feedback on - yet it is a competency that many employers require.

\section{Information Technology skills}

A significant improvement is shown in all categories here, particularly in the response that indicates that participants felt they are 'extremely good' at this skill in the workplace. This could be the result of training provided by the employers or sustained practice within the organisation's IT environment.

\section{Skills ranking}

The survey also asked participants to rank each of these six skills in the order of which feedback during the module has helped most in the workplace tasks. Feedback provided on communication and interpersonal skills was regarded as being the most useful, whilst the feedback related to professional conduct was found be the least useful. Professional conduct, it seems is best learnt within the workplace.

In the context of the work-related module, respondents preferred feedback to be either verbally provided or as short comments on their work. They preferred not be given feedback as a group or even a small team and less than half the respondents placed value on the final grade as a means of valuable feedback.

\section{Discussion arising from interviews}

The interviewing process was based on a series of semi-structured questions to cover those aspects in the workplace that were challenging and to gauge the extent to which 
the feedback given during the work-related learning module helped or is helping. The most overwhelming aspect to arise from these discussions was the stark difference in feedback given to assessment and the feedback given in terms of performance and capability at work. All participants, even those that were employed on a temporary or voluntary capacity, felt strongly that they had not been prepared for receiving what was sometimes felt to be quite harsh and very direct feedback on their performance at work. A number of respondents had undergone a formal appraisal process and perceived that nothing at university had prepared them for it. Examples of aspects of appraisal processes which graduates would not have come across typically include objectivesetting with targets and stretch targets, financial as well as non-financial objectives, accountabilities and goals, key indicators, self-assessment and forward-looking development plans.

Another area that caused some concern is around the terminology for competencies used widely in industry. Participants believed that they did not have a clear understanding of how to evidence competency and therefore were unable to adequately relate their abilities to employers. Examples of desirable competencies used by many organisations including a prominent magic circle employer, include 'cultural awareness and sensitivity', 'resilience', 'following through', 'business alignment', 'judgement' and 'influence'. Participants felt that some awareness of the language of competency as utilised in industry could have been usefully included in the work-related learning module.

All participants related a considerable difference in their experience of the work undertaken for the work-related learning module itself (even where it was for an industry-based client) and the work they were now doing at the workplace; with many citing the 'pressure to produce' as being infinitely more challenging in the workplace.

\section{Conclusions}

The concept of work-readiness has come to mean framing the academic curriculum with sufficient opportunities for gaining the experience of work as possible and thereby developing those employability skills that industry demands of new graduates. However, what of the graduates themselves? They also need to be prepared for the manner in which employers will measure and reward their performance. This study has revealed that work-related learning does play an important role in allowing students to acquire and/or improve employability skills but that more can be done during this experience, for example, to expose them to the formal appraisal schemes utilised in the workplace. Also it can be argued that HE fails to cultivate within the classroom the ability of new graduates to respond to the 'pressure to produce' which they will face in the workplace.

As a result of these findings, the learning agreement used in the work-related learning module requires enhancement to reflect industry-style appraisal formats using competency terminology commonly used for that process. Students should ideally be exposed to setting their own targets and stretch targets within a more direct and formalised feedback environment; thereby developing a degree of maturity in students. It is evident that negotiated learning agreements as used in work-related learning initiatives need further enhancements to align them better to the performance measuring tools used in industry. Also evident is that students need to be better equipped to learn 
how to negotiate and reflect on their professional practice and thereby avoid the reality check.

Acknowledgement: Thanks to ALDinHE (The Association for Learning Development in Higher Education) for financial support of this project.

\section{References}

Clements, M. D., \& Cord, B. A. (2013). Assessment Guiding Learning: Developing Graduate Qualities in an Experiential Learning Programme. Assessment \& Evaluation in Higher Education, 38(1), 114-124.

Evans, C. (2013). Making Sense of Assessment Feedback in Higher Education. Review of Educational Research, 83(1), 70-120.

Hopkins, E. A. (2008). Work-related learning: hearing students' voices. Educational Action Research, 16(2), 209-219.

Jackson, D. (2014). Self-assessment of employability skill outcomes among undergraduates and alignment with academic ratings. Assessment \& Evaluation in Higher Education, 39(1), 53-72. doi: 10.1080/02602938.2013.792107

Jessop, T., El Hakim, Y., \& Gibbs, G. (2014). The whole is greater than the sum of its parts: a large-scale study of students' learning in response to different programme assessment patterns. Assessment \& Evaluation in Higher Education, 39(1), 73-88. doi: 10.1080/02602938.2013.792108

Jollands, M., Jolly, L., \& Molyneaux, T. (2012). Project-based learning as a contributing factor to graduates' work readiness. European Journal of Engineering Education, 37(3), 143-154.

Josephine H. Lappia. (2011). Towards design guidelines for work related learning arrangements. Journal of European Industrial Training, 35(6), 573-588. doi:10.1108/03090591111150103

McKinnon, S., \& McCrae, J. (2012). Closing the Gap: Preparing Computing Students for Employment through Embedding Work-Related Learning in the Taught Curriculum. Industry and Higher Education, 26(4), 315-320.

Rowe, A. D., \& Wood, L. N. (2008). Student Perceptions and Preferences for Feedback. Asian Social Science, 4(3), 78-88.

Simons, P. R.-J., \& Ruijters, M. C. P. (2008). Varieties of work related learning. Organisational and Personal Contributions to Workplace Learning Environments, 47(4), 241-251. doi:10.1016/j.ijer.2008.07.001

Venables, A., \& Tan, G. (2009). Realizing Learning in the Workplace in an Undergraduate IT Program. Journal of Information Technology Education, 8, IIP-17. 